\title{
Understanding household income poverty at small area level
}

Robert Fry, Office for National Statistics

\section{Abstract}

A new ONS data release provides experimental estimates of the proportion of households in poverty, after housing costs, at Middle Layer Super Output Area (MSOA) level in England and Wales. These complement the experimental estimates of average household income for MSOAs already published by ONS.

These estimates are based on Family Resources Survey (FRS) data and the Department for Work and Pensions (DWP) publication Household Below Average Income derived from FRS data. They use a similar modelling approach to that used for the average household income estimates. The first set of these estimates relate to the $2007 / 08$ period. Future updates will be released alongside the estimates of average household income.

This article looks at spatial patterns in the proportion of households in poverty, in particular looking at how poverty is distributed within regions and local authorities. The article shows that there are wide variations in the patterns of the proportions of households in poverty in each region. Looking across all MSOAs, Wales, the North East and London had the highest median values of the proportion of households in poverty ${ }^{1}$. London had the largest spread, that is, it had both areas with very low and high proportions of households in poverty.

The article also provides an introduction to these estimates and some summary guidance on their use. It will be of interest to people with a focus on poverty at a local level such as politicians, charities, planners, regeneration specialists, and academics.

\section{Introduction}

This article focuses on the newly released model-based estimates of households in poverty for Middle Layer Super Output Areas (MSOAs) produced by the Office for National Statistics (ONS). It aims to introduce readers to these estimates and to explore how income poverty is spread within regions, and local areas.

This article builds upon the article Bond S, Campos C (2010) 'Understanding income at small area level', Regional Trends 42, pp 80-942, which explored the closely associated model-based estimates of average (mean) household income. The new model-based estimates of the proportion of households in poverty for England and Wales have been produced in response to user demand for specific poverty measures at a small area level. This article will be of interest to those wanting

\footnotetext{
${ }^{1}$ Official estimates of the proportions of individuals in low income by region are given in the Households Below Average Income publication at http://research.dwp.gov.uk/asd/index.php?page=hbai.

${ }^{2}$ The article can be found at: www.statistics.gov.uk/cci/article.asp? ID $=2422$
} 
to know more about these new estimates and those with a focus on poverty at a local level such as politicians, charities, planners, regeneration specialists, and academics.

The article consists of the following sections:

- An introduction to the model-based estimates of households in poverty and how they can be used

- A study of how income poverty was distributed across and within Wales and the nine regions of England

- A study of income poverty in two example local authorities which provides examples of the how the data can be explored at this local level

\section{Small area proportions of households in poverty, 2007/08}

The word 'poverty' can be used to describe different things. It can be used as an all-encompassing term to describe situations where people lack many of the opportunities that are available to the average citizen, but in other situations the word might be used to describe low income, excluding other factors associated with social exclusion and disadvantage. These estimates focus solely on the low income element of poverty.

The new model-based estimates of the proportion of households in poverty for England and Wales are estimates for MSOAs based on the Family Resources Survey (FRS) and Households Below Average Income data (HBAI) for 2007/08 and other administrative data (for example, Census 2001 data, DWP benefit claimant counts).

The measure of poverty used is the proportion of households below 60 per cent of the UK median net equivalised household income after housing costs. It is the same concept as that used in the HBAI estimates, published by the Department for Work and Pensions (DWP), which uses the UK median. For 2007/08 the HBAI report specified the income threshold for a household defined as living in poverty was below $£ 199$ per week after housing costs for a couple with no children. This was the threshold used in the modelling process for the estimates and is the threshold used throughout this article to define a household in poverty.

Unlike the model-based income estimates, only one measure is produced for the estimates of the proportion of households in poverty; this is the proportion of households in poverty after housing costs (AHC). Research was also conducted on a model for the proportion of households in poverty before housing costs (BHC). This is not included in this release as this model was found to have less stability over time than the AHC model. Further development work on this model is currently being carried out by ONS. Therefore the data presented in this article are always based on income after housing costs.

The income data feeding into the estimation have been equivalised. Equivalisation adjusts the income estimates to take account of household size and composition, so that poverty can more accurately be assessed between households of different sizes. The equivalisation used was the modified OECD scale ${ }^{3}$.

\footnotetext{
${ }^{3}$ For more information the OECD method of equivalisation see: Economic and Labour Market Review, Vol 14, No 1, January 2010, Grace Anyaegbu. www.statistics.gov.uk/cci/article.asp?ID=2349
} 
These estimates are currently classed as experimental statistics but are likely to undergo assessment against the Code of Practice for Official Statistics during 2011, together with the model-based mean income estimates. We encourage readers to use these estimates and to provide feedback on their quality and usefulness, which will be considered as part of the assessment.

For further information on these estimates, including technical documentation and user guides, please explore the metadata that accompanies the estimates.

\section{Box 1: $\quad$ Model-based estimates}

The model-based approach to producing the estimates is based on determining a relationship between households below 60 per cent of UK equivalised median income as measured by the FRS and HBAI, and administrative data for MSOAs. The FRS and HBAI do not cover every MSOA and so once a relationship is established between the administrative data and the FRS and HBAI data, the administrative data (available for every MSOA) are used to estimate the proportion of households below 60 per cent of the UK median income. This process is called 'borrowing strength' and produces a set of unbiased and consistent small area estimates that could not be produced from either source in isolation.

The main limitation of the estimates for small areas is that they are subject to uncertainty due to survey sampling and the modelling process. ONS has produced confidence intervals associated with the estimates to make the accuracy of the estimates clear. The model-based confidence intervals provide a range for the proportion of households in poverty for each MSOA, which indicates the uncertainty or precision of each estimate. This uncertainty is a measure of potential departure for each MSOA from the fitted model; the confidence intervals indicate the ranges that for approximately $95 \%$ of MSOAs will contain the true value

\section{Box 2: Guidance on using these estimates}

There are currently three main considerations when using these estimates.

Other geographical areas. The MSOA estimates can be aggregated to provide the proportion of households in poverty for higher geographical levels, for example, local authorities. However, no associated measure of accuracy is available for aggregated estimates.

Ranking. Care needs to be taken when using ranks based on the MSOA estimates due to the uncertainty around each MSOA estimate.

Extreme areas. The modelling process tends to shrink estimates towards the average level, so the true distribution of MSOA proportion of households in poverty will have more extreme high and low values than the estimated proportions. 


\section{Regional patterns of the proportion of households in poverty}

\section{Income distribution within English regions and Wales}

Regional estimates of the pattern of poverty are already available from the HBAI report published by DWP. These are direct estimates from the survey which at this level give acceptable precision. However, while these estimates show the relative levels across England and Wales, they do not show the variability in the proportion of households in poverty within each region. The new MSOA estimates are useful for exploring how poverty varies at a lower geographical level within each region.

These MSOA estimates have been calibrated to ensure that when they are aggregated to regional level, the resulting regional estimate agrees with the direct estimate obtained using household records included in the analysis. Specifically, these are all household records which show weekly household income (equivalised after housing costs) exceeding zero.

Figure 1 shows the distribution of the proportion of households in poverty after housing costs for MSOAs within each English region and Wales in 2007/08. The orange line denotes the median value of the proportion of households in poverty for each region, looking across all MSOAs. This shows that Wales, the North East and London had the highest median values of households in poverty. The South East and East of England had the lowest median value of households in poverty.

The region which had the broadest distribution of proportions of households in poverty was London, this was followed by the West Midlands which also had a reasonably broad distribution, and generally more MSOAs with higher proportions of households in poverty compared with other regions.

The average MSOA proportion of households in poverty was more tightly distributed in other regions. Wales and the South West were the most tightly distributed although centred on different proportions of households in poverty. 


\section{Figure 1 Distribution of MSOA proportion of households in poverty,} Per cent of MSOAs 2007/08

in region North East

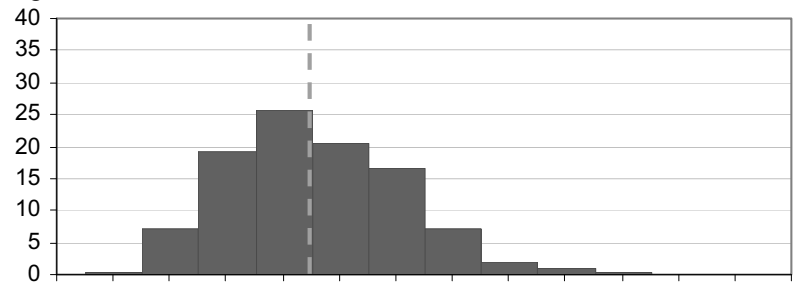

$\begin{array}{llllllllllll}0.08 & 0.13 & 0.18 & 0.23 & 0.28 & 0.33 & 0.38 & 0.43 & 0.48 & 0.53 & 0.58 & 0.63\end{array}$ Proportion of Households in Poverty

Yorkshire and The Humber

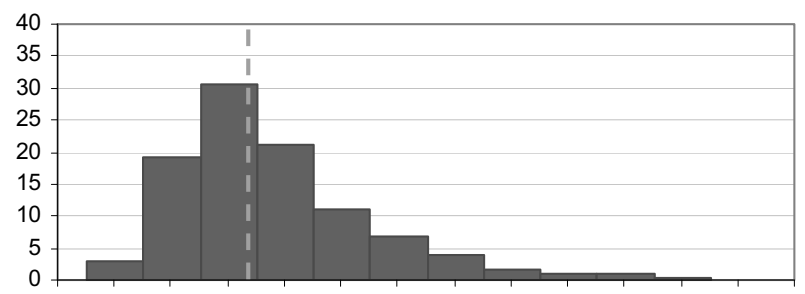

$\begin{array}{llllllllllll}0.08 & 0.13 & 0.18 & 0.23 & 0.28 & 0.33 & 0.38 & 0.43 & 0.48 & 0.53 & 0.58 & 0.63\end{array}$ Proportion of Households in Poverty

West Midlands

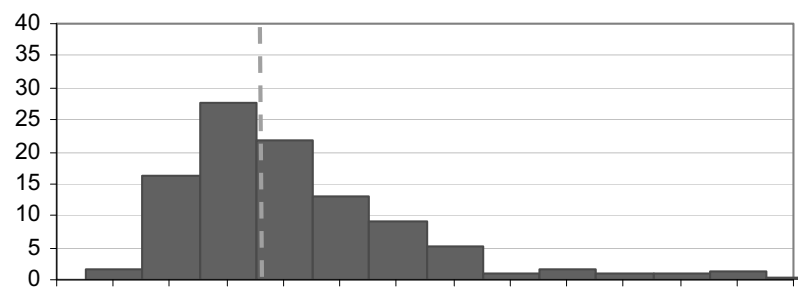

$\begin{array}{llllllllllll}0.08 & 0.13 & 0.18 & 0.23 & 0.28 & 0.33 & 0.38 & 0.43 & 0.48 & 0.53 & 0.58 & 0.63\end{array}$ Proportion of Households in Poverty

London

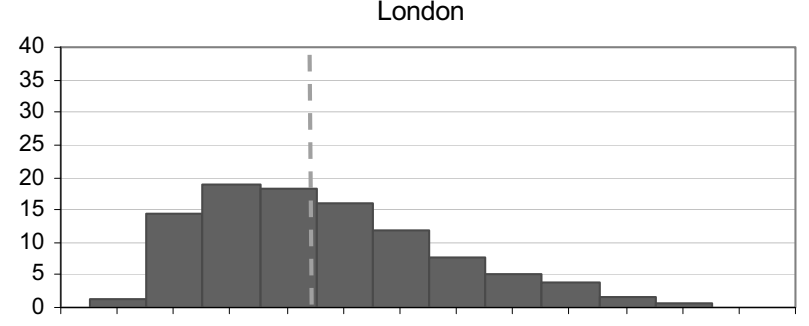

$\begin{array}{llllllllllll}0.08 & 0.13 & 0.18 & 0.23 & 0.28 & 0.33 & 0.38 & 0.43 & 0.48 & 0.53 & 0.58 & 0.63\end{array}$ Proportion of Households in Poverty

South West

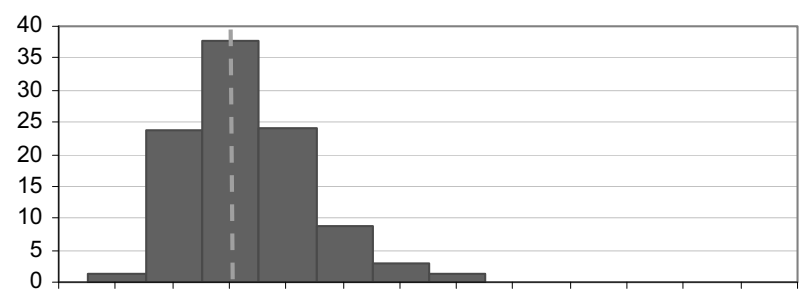

$\begin{array}{llllllllllll}0.08 & 0.13 & 0.18 & 0.23 & 0.28 & 0.33 & 0.38 & 0.43 & 0.48 & 0.53 & 0.58 & 0.63\end{array}$ Proportion of Households in Poverty

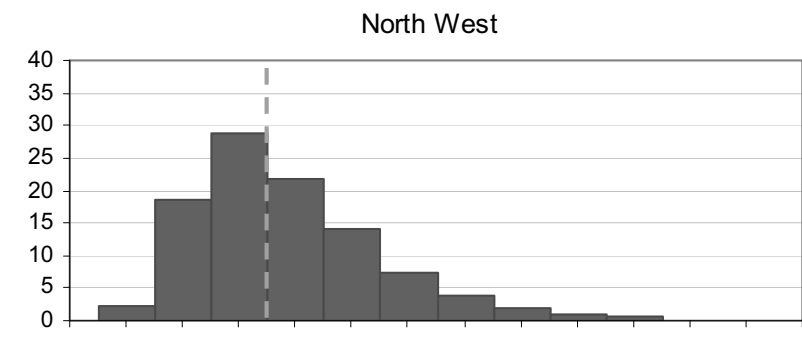

$\begin{array}{llllllllllll}0.08 & 0.13 & 0.18 & 0.23 & 0.28 & 0.33 & 0.38 & 0.43 & 0.48 & 0.53 & 0.58 & 0.63\end{array}$ Proportion of Households in Poverty

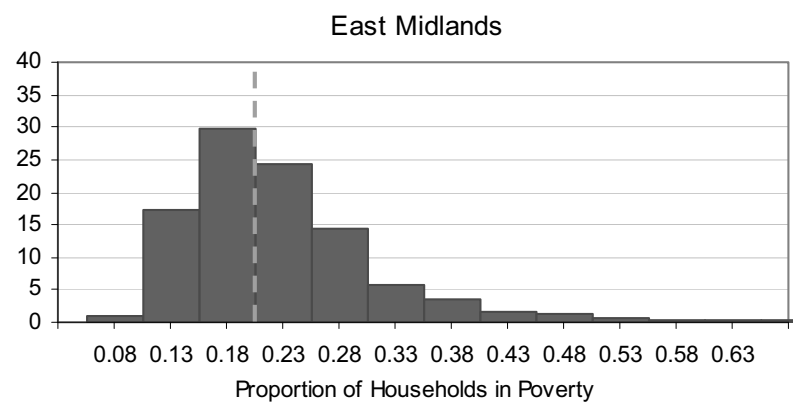

East of England

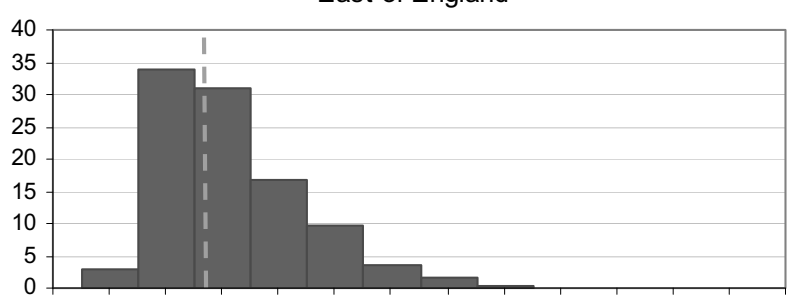

$\begin{array}{llllllllllll}0.08 & 0.13 & 0.18 & 0.23 & 0.28 & 0.33 & 0.38 & 0.43 & 0.48 & 0.53 & 0.58 & 0.63\end{array}$ Proportion of Households in Poverty

South East

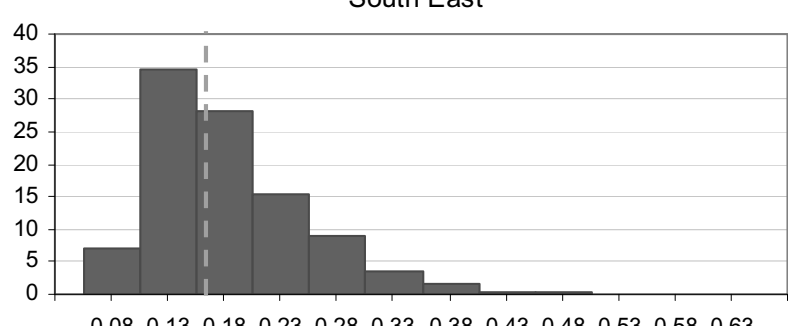

$\begin{array}{llllllllllll}0.08 & 0.13 & 0.18 & 0.23 & 0.28 & 0.33 & 0.38 & 0.43 & 0.48 & 0.53 & 0.58 & 0.63\end{array}$ Proportion of Households in Poverty

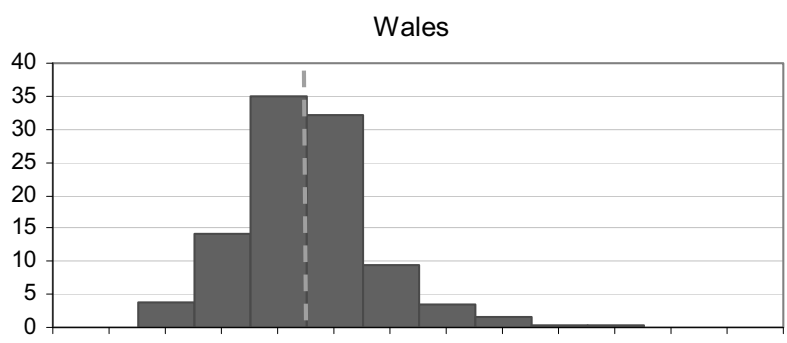

$\begin{array}{llllllllllll}0.08 & 0.13 & 0.18 & 0.23 & 0.28 & 0.33 & 0.38 & 0.43 & 0.48 & 0.53 & 0.58 & 0.63\end{array}$ Proportion of Households in Poverty

Note: These charts show the percentage of MSOAs in a region that had proportions of poverty indicated by the horizontal axis. The orange line denotes the median value of the proportion of households in poverty for each region.

Source: Office for National Statistics, model-based estimates 


\section{Box 3 Spread of income}

Four percentiles are used to help determine the spread of households in poverty within each region.

- P10 (lower decile): the proportion of households in poverty below which 10 per cent of MSOAs lie

- P25 (first quartile): the proportion of households in poverty below which 25 per cent of MSOAs lie

- P75 (third quartile): the proportion of households in poverty below which 75 per cent of MSOAs lie

- P90 (upper decile): the proportion of households in poverty below which 90 per cent of MSOAs lie

Percentiles are defined in three different ways in this article:

- Nationally, using all MSOAs in England and Wales

- Regionally, using all MSOAs within a region

- Locally, using all MSOAs within a local authority

The spread of households in poverty is defined by the ratios of these percentiles. Typically, such ratios are used to compare the incomes of one area or person at the 90th percentile relative to the area or person at the 10th percentile. In this case the ratio is being used in a different scenario; to compare the proportion of households in poverty in different areas.

- P90/P10 is the spread of the extreme proportions of households in poverty

- P75/P25 is the spread of the central part of the distribution

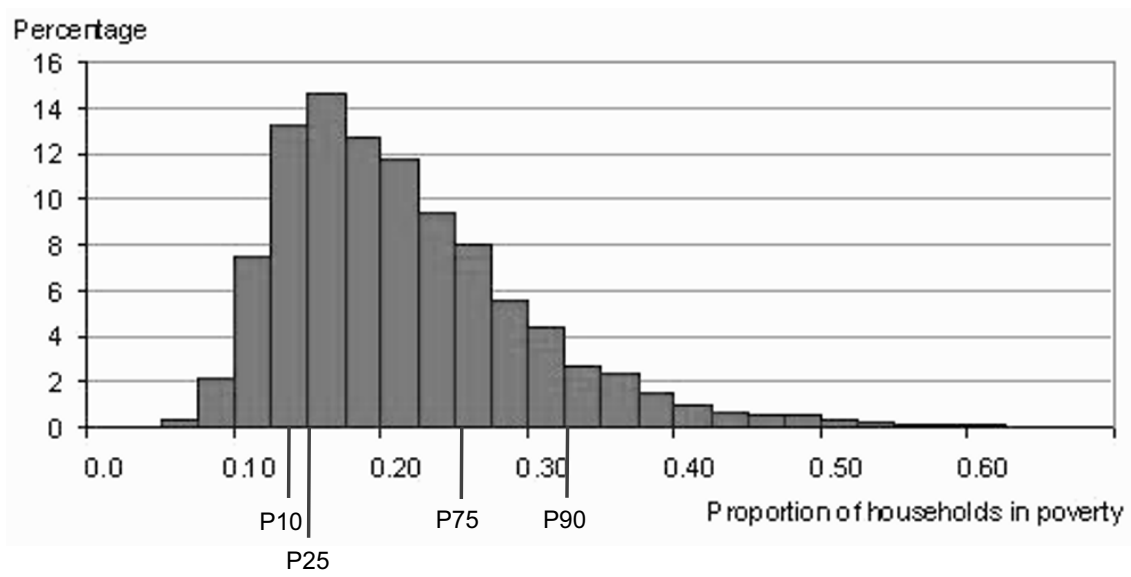

Example calculation of P90/P10 ratio:

$\mathrm{P} 90=0.33, \mathrm{P} 10=0.13$

$\mathrm{P} 90 / \mathrm{P} 10=0.33 / 0.13=2.62 \quad$ or $\quad \mathrm{P} 90$ is 162 per cent bigger than $\mathrm{P} 10$

So the lowest proportion of households in poverty in the upper 10 per cent group of MSOAs is 162 per cent bigger than the highest proportion of households in poverty in the lowest 10 per cent group of MSOAs. 
Table 2

\section{Thresholds and ratios for MSOA proportion of households in poverty}

England and Wales, 2007/08 (ranked by P75/P25 ratio)

\begin{tabular}{|c|c|c|c|c|c|c|}
\hline & P10 & P25 & P75 & P90 & P75/P25 & P90/P10 \\
\hline Wales & 0.17 & 0.22 & 0.28 & 0.32 & 1.28 & 1.82 \\
\hline South West & 0.13 & 0.15 & 0.22 & 0.26 & 1.47 & 2.04 \\
\hline North East & 0.17 & 0.20 & 0.31 & 0.35 & 1.56 & 2.09 \\
\hline East & 0.12 & 0.14 & 0.22 & 0.27 & 1.58 & 2.37 \\
\hline East Midlands & 0.14 & 0.16 & 0.26 & 0.33 & 1.60 & 2.36 \\
\hline North West & 0.13 & 0.16 & 0.26 & 0.33 & 1.65 & 2.52 \\
\hline Yorkshire and The Humber & 0.13 & 0.15 & 0.25 & 0.33 & 1.66 & 2.64 \\
\hline South East & 0.11 & 0.13 & 0.21 & 0.27 & 1.66 & 2.53 \\
\hline West Midlands & 0.13 & 0.16 & 0.28 & 0.36 & 1.74 & 2.70 \\
\hline London & 0.14 & 0.17 & 0.32 & 0.41 & 1.86 & 3.00 \\
\hline All MSOAs & 0.13 & 0.15 & 0.26 & 0.33 & 1.69 & 2.62 \\
\hline
\end{tabular}

Source: Office for National Statistics, model-based estimates

The spread of income is explored numerically in Table 2 using percentiles (P10, P25, P75 and P90 thresholds) and two ratios P90/P10 and P75/P25 (see Box 3 for a full explanation of the percentiles and the ratios). These percentiles are calculated from the MSOAs within each region.

Table 2 shows that in England and Wales 10 per cent of all MSOAs had proportions of households in poverty below 13 per cent and a quarter had proportions of households in poverty below 15 per cent. At the upper end of the distribution a quarter of all MSOAs had a proportion of households in poverty above 26 per cent and 10 per cent of all MSOAs had a proportion above 33 per cent. The P90/P10 ratio for all MSOAs in England and Wales was 2.62. This means that the upper decile (P90) of MSOAs was 162 per cent higher than the lowest decile (P10) of households in poverty. The $\mathrm{P} 75 / 25$ ratio of 1.69 means that the upper quartile of the distribution was 69 per cent higher than the lower quartile.

The region with the smallest ratios, for both the P75/25 and P90/P10, was Wales. This confirms what was shown in Figure 1. For MSOAs in Wales the upper 10 per cent of the distribution (P90) was 82 per cent higher than the lower 10 per cent of the distribution. For the centre of the distribution the upper quartile (P75) was 28 per cent higher than the lower quartile (P25). This was the narrowest spread of the proportions of households in poverty compared with all the other English regions. The next narrowest spread was in the South West where the upper quartile (P75) was 47 per cent higher than the lower quartile (P25).

The area with the largest ratios (and therefore spread), for both the P75/25 and P90/P10, was London. The upper quartile (P75) was 86 per cent higher than the lower quartile (P25). The upper 10 per cent of the distribution (P90) was 200 per cent higher than the lower 10 per cent of the distribution (P10). The West Midlands had the next widest spread, where the upper quartile (P75) was 74 per cent higher than the lower quartile, while the upper 10 per cent of the distribution (P90) was 170 per cent higher than the bottom 10 per cent of the distribution. 
The percentiles also give some information about the distribution of poverty in an area. By definition, a tenth of MSOAs have poverty rates below the P10 value. The South East had the lowest $\mathrm{P} 10$ value of 0.11 which means that 10 per cent of MSOAs in the South East had a proportion of households in poverty below 0.11 . The $\mathrm{P} 10$ values for most regions were reasonably similar, with proportions of households in poverty below 0.12 to 0.14 . Wales and the North East had higher P10 values; 10 per cent of the MSOAs in these regions had a proportion of households in poverty below 0.17 .

A tenth of all MSOAs have poverty rates above the P90 value. London had by far the highest P90 value; 10 per cent of MSOAs in this region had a proportion of households in poverty of at least 0.41 . The area with the next highest P90 value was the West Midlands which had a P90 value of 0.36 . The South West had the lowest P90 value; 10 per cent of MSOAs in the region had a proportion of household in poverty of 0.26 or more. The South East and East of England had similar P90 values; 10 per cent of MSOAs in these regions had a proportion of households in poverty of at least 0.27 .

All of these results provide a useful insight into how the estimates of households in poverty at a low level geography can be used to highlight interesting patterns across the regions of England and Wales.

\section{Spatial patterns of households in poverty}

Map 3 shows the pattern of MSOAs which had the highest and lowest proportions of households in poverty within England and Wales.

The patterns shown in Map 3 reveal that the highest proportions of households in poverty (grey circles) were not confined to one region or area. The MSOAs with the highest proportions of households in poverty tend to be centred on the larger urban metropolitan areas; areas such as London, Birmingham, Manchester, Leeds, Liverpool, Newcastle, Middlesbrough, Leicester and Cardiff. The number of MSOAs with high proportions of households in poverty seemed to be linked to the size of the city. London contained about 32 per cent of MSOAs with the highest proportions of households in poverty, while the West Midlands, in which Birmingham is located, contained about 15 per cent of all MSOAs with the highest proportions of households in poverty.

In contrast Map 3 also shows that the majority of MSOAs with the lowest proportions of households in poverty (blue stars) were not confined to the large urban metropolitan areas and the majority seem to be located in more rural areas. This is consistent with the previous Bond and Campos article which appeared to highlight that areas with the highest household incomes were in the centre of urban areas as well as satellite areas, both urban and rural, around large urban conurbations. The South East had a large share of the MSOAs with the lowest proportions of households in poverty, 41 per cent of all MSOAs. This seems to be a London effect as many of the MSOAs with the lowest proportions of households in poverty appear to surround London. The East of England had the next largest share containing 14 per cent of all MSOAs with the lowest proportions of households in poverty; again these appear to surround London. 


\section{Map 3 High and low levels of households in poverty}

England and Wales MSOAs, 2007/08

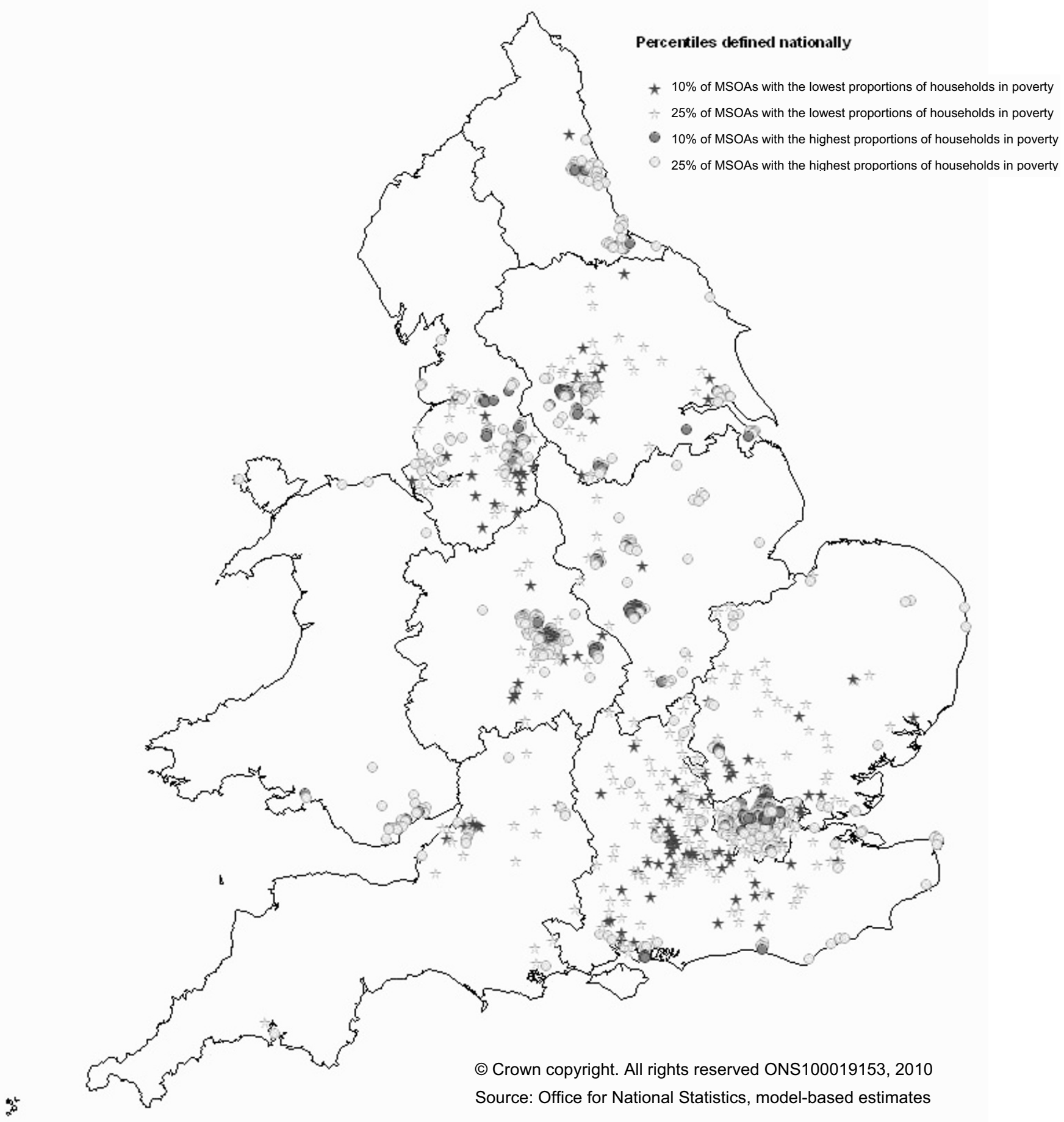

Note: When looking at spatial patterns of the proportions of households in poverty it is important that model uncertainty is taken into consideration. MSOAs were only highlighted on the map if their entire 95 per cent confidence interval lay within the respective percentile thresholds. This therefore shows the areas which we were very confident had high or low proportions of households in poverty. 


\section{Analysis of the proportion of households in poverty within a region}

This section uses percentiles that are defined regionally to analyse the spatial patterns of households in poverty within a region. By defining percentiles at a regional level the analysis ignores the rest of the country and therefore paints a comparative picture within a region.

\section{Map $4 \quad$ High and low levels of households in poverty}

MSOAs in West Midlands, 2007/08

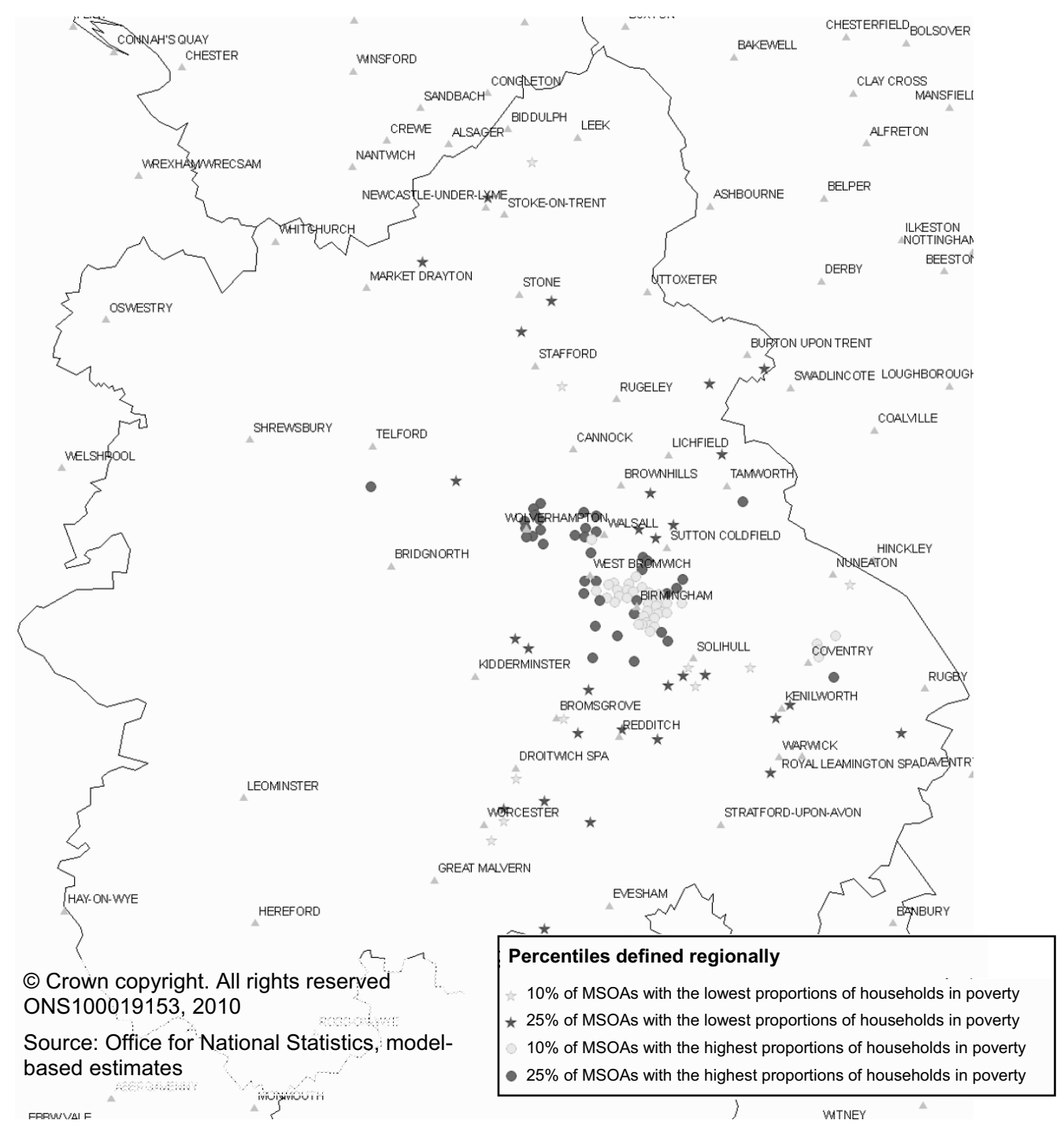

Note: Only the MSOAs whose entire confidence interval lay within the respective thresholds were included on the map. This takes model uncertainty into account so we can be confident that only areas with high or low proportions of households in poverty were included.

This section uses the West Midlands as an example region. Map 4 shows the MSOAs with the highest and lowest proportions of households in poverty. It shows a similar pattern to that shown at the national level. It is clear that the urban areas around Birmingham, Wolverhampton, West Bromwich and Coventry have clusters of MSOAs that had the highest levels of households in poverty, indicated by the grey circles. 
The areas with the lowest proportions of households in poverty are indicated by the blue stars. These MSOAs tend not to be in the main large urban metropolitan areas and tend to be in either smaller urban areas such as Worcester and Kenilworth, or in the surrounding rural areas.

\section{Local patterns of income}

This analysis looks at the proportion of households in poverty within example local authorities in the West Midlands, Birmingham and Solihull - two neighbouring local authorities.

Table 5 provides data for these areas, such as the number of MSOAs, average proportions of households in poverty and the percentiles defined locally for each local authority. This shows that the populations of Birmingham and Solihull are very different as they contain 131 and 29 MSOAs with total populations of $1,028,700$ and $205,200^{4}$ respectively. The average proportion of households in poverty in Birmingham was 0.33 while in Solihull this was 0.18 . However the spread of households in poverty ${ }^{5}$ was of a similar magnitude in both local authorities. This seems to suggest that the spread of proportions of households in poverty is not linked to the average proportion of households in poverty. This finding is mirrored by the charts in figure 2 where Wales and the South West had similar distributions but had different overall average proportions of households in poverty.

\section{Table 5 Distribution of households in poverty}

MSOAs in Birmingham and Solihull, 2007/08

\begin{tabular}{|c|c|c|c|c|c|}
\hline Local authority & $\begin{array}{l}\text { Number of } \\
\text { MSOAs }\end{array}$ & $\begin{array}{c}\text { Average } \\
\text { proportion of } \\
\text { households in } \\
\text { poverty }\end{array}$ & P10 & P90 & P90 / P10 \\
\hline Birmingham & 131 & 0.33 & 0.18 & 0.57 & 3.23 \\
\hline Solihull & 29 & 0.19 & 0.09 & 0.33 & 3.67 \\
\hline
\end{tabular}

Source: Office for National Statistics, model-based estimates

Maps 6 and 7 show the spatial pattern of the proportion of households in poverty in each local authority. To provide a meaningful spatial comparison between these two local authorities the percentiles, which highlight areas with both high and low levels of households in poverty, were calculated at the regional level using all of the MSOAs. Therefore the colours in both maps are based upon the same threshold.

Aerial mapping is used as a background image in the maps to give some understanding of the nature of each MSOA, that is, whether the MSOA is part of a large urban area, a suburb or a rural area.

Map 6 shows that in the centre of Birmingham there was a large cluster of MSOAs with some of the highest proportions of households in poverty in the region, above the P75 and P90 thresholds. There were also areas to the south and west of Birmingham that had high proportions of households in poverty above the P75 threshold.

\footnotetext{
${ }_{5}^{4}$ Source: ONS Mid-2009 Population Estimates www.statistics.gov.uk/statbase/Product.asp?vlnk=15106

${ }^{5}$ measured by the P90/P10 ratio
} 
There was only one MSOA below the P25 threshold (in blue) highlighting that this MSOA, to the north of Birmingham, had one of the lowest proportions of households in poverty.

The location of the areas with the highest and lowest proportions of households in poverty appears to tie in with the national picture which showed that MSOAs with the highest proportions of households in poverty fell in metropolitan areas and MSOAs with the lowest proportions of households in poverty were in the more rural areas. The aerial photography included in Map 6 confirms this with the only MSOA below the P25 threshold appearing in a comparatively sparsely populated area including fields.

\section{Map $6 \quad$ Local patterns of households in poverty}

MSOAs in Birmingham, 2007/08

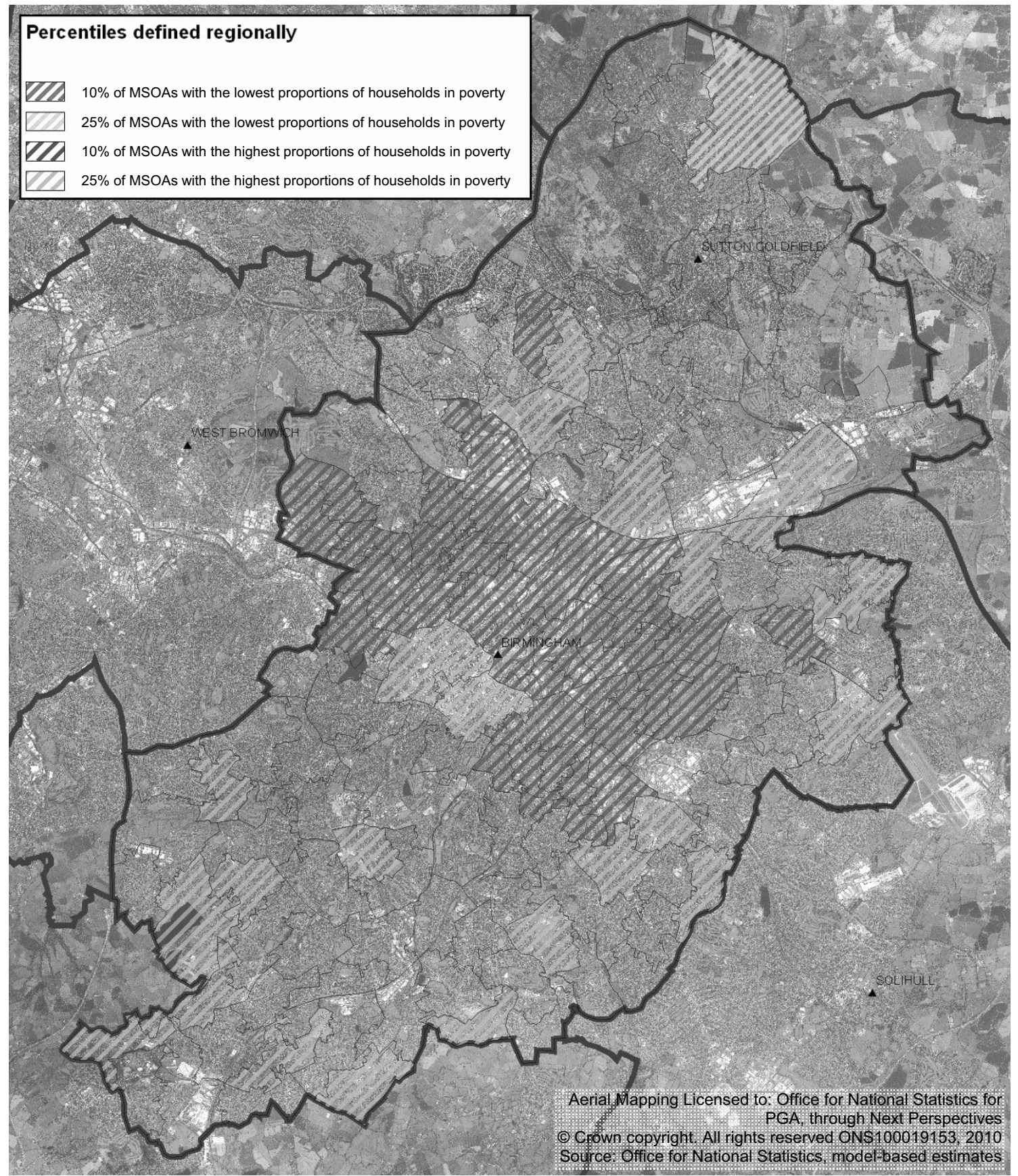




\section{Map $7 \quad$ Local patterns of households in poverty}

MSOAs in Solihull, 2007/08

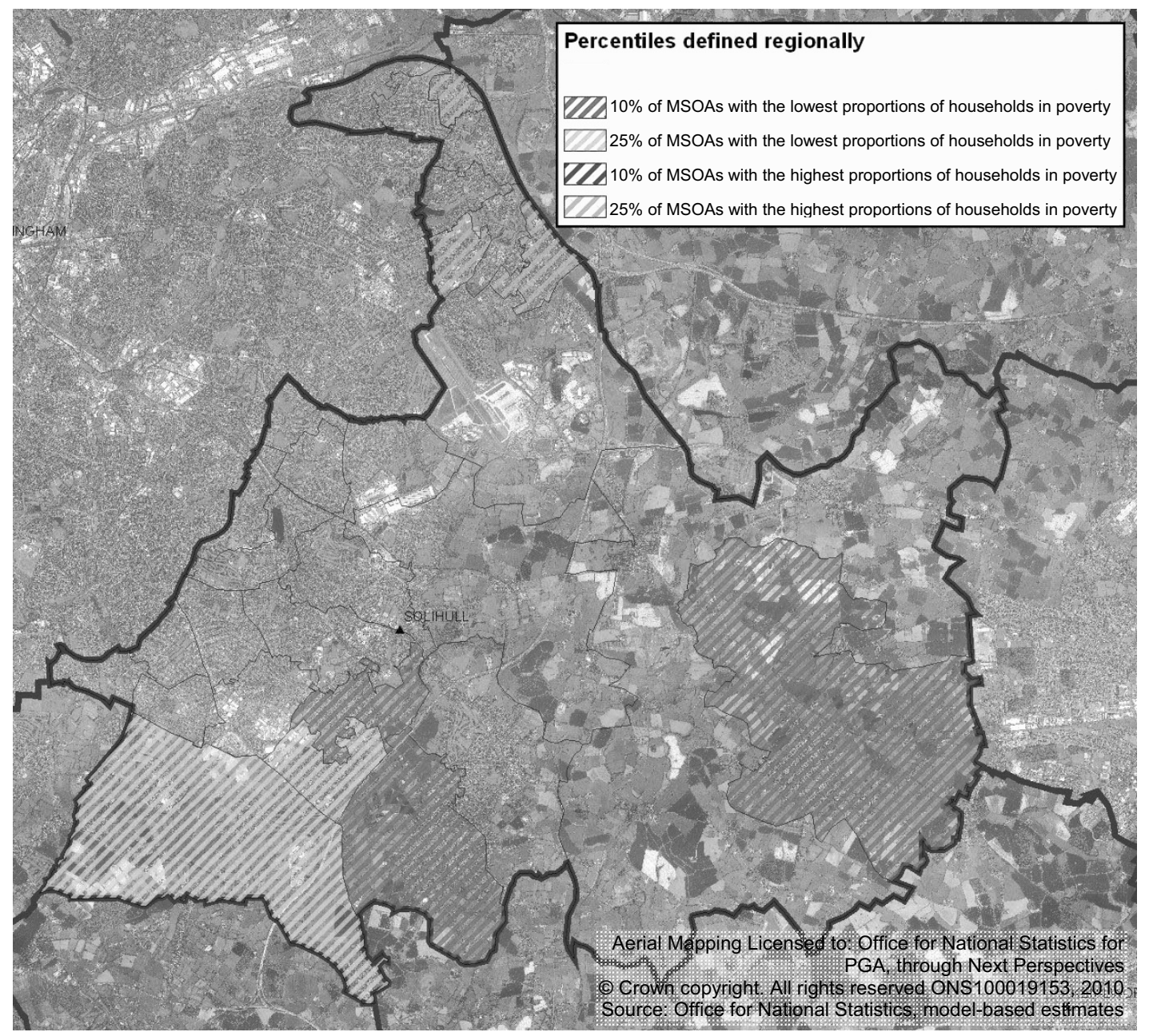

Solihull neighbours Birmingham to the south east and looking at the aerial photography it is clear that it has a lot more green space than Birmingham, but also contains the fringe of Birmingham and smaller urban areas.

Map 7 shows that Solihull has several MSOAs in the south that had low proportions of households in poverty below the P25 threshold and some below the P10 threshold. Looking at the aerial mapping for these MSOAs suggests that these areas are more sparsely populated compared with other areas. To the north of Solihull there are a few MSOAs that had some of the highest proportions of households in poverty, above the P75 threshold for the region. These appear to be urban areas on the eastern fringe of Birmingham.

\section{Local authorities with the highest and lowest proportions of households in poverty}

It can become difficult to analyse the spread of poverty at the local authority level because of the small number of MSOAs that some local authorities contain. At the most extreme the Isles of Scilly and City of London have only one MSOA each. It is more sensible to look at the average proportions of households in poverty; although note that areas with fewer MSOAs are subject to larger confidence intervals. 
Table 8 and Table 9 show the local authorities with the lowest and highest average proportion of households in poverty respectively.

Table 8 shows that all of the local authorities with the lowest proportions of households in poverty are in the South East and East of England regions which both surround London. This supports the national picture explored in Map 3. Hart, a district in north east Hampshire, is the local authority with the lowest proportion of households in poverty where around 10 per cent of households are in poverty.

\section{Table $8 \quad$ Local authorities with the lowest average proportion of households in poverty}

England and Wales, 2007/08

\begin{tabular}{llr}
\hline Rank & \multicolumn{1}{c}{ Local authority } & \multicolumn{1}{c}{$\begin{array}{c}\text { Average proportion of } \\
\text { households in poverty }\end{array}$} \\
\hline 1 & Hart (Hampshire) & 0.10 \\
2 & Wokingham UA & 0.11 \\
3 & Surrey Heath (Surrey) & 0.12 \\
4 & South Cambridgeshire (Cambridgeshire) & 0.12 \\
5 & Chiltern (Buckinghamshire) & 0.13 \\
6 & Uttlesford (Essex) & 0.13 \\
7 & South Oxfordshire (Oxfordshire) & 0.13 \\
8 & Horsham (West Sussex) & 0.13 \\
9 & St Albans (Hertfordshire) & 0.13 \\
10 & Mid Sussex (West Sussex) & 0.13 \\
\hline
\end{tabular}

* Where the local authority belongs to a county the county name is provided in brackets \# Excludes City of London as figure would be based on a single MSOA and could be considered much less robust compared to other local authorities

† This figure is based on averaged MSOA data, that is, all the MSOA proportions of households in poverty are summed and divided by the number of MSOAs in the local authority, giving the average

Source: Office for National Statistics, model-based estimates 
Table 9 shows that most of the local authorities with the highest proportion of households in poverty are in urban metropolitan type areas. Six of the local authorities with the highest proportion of households in poverty are in London, with Tower Hamlets the area with the highest proportion of households in poverty. Other large urban areas, Leicester, Birmingham, Manchester and Nottingham also had a high proportion of households in poverty.

\section{Table $9 \quad$ Local authorities with the highest average proportion of households in poverty, 2007/08}

England and Wales, 2007/08

\begin{tabular}{llr}
\hline Rank & \multicolumn{1}{c}{ Local authority } & $\begin{array}{c}\text { Average proportion of } \\
\text { households in poverty }\end{array}$ \\
\hline 1 & Tower Hamlets & 0.44 \\
2 & Newham & 0.39 \\
3 & Leicester & 0.37 \\
4 & Hackney & 0.37 \\
5 & Birmingham & 0.33 \\
6 & Manchester & 0.33 \\
7 & Brent & 0.32 \\
8 & Southwark & 0.32 \\
9 & Nottingham & 0.31 \\
10 & Barking and Dagenham & 0.30 \\
\hline
\end{tabular}

† This figure is based on averaged MSOA data, that is, all the MSOAs proportions of households in poverty are summed and divided by the number of MSOAs in the local authority, giving the average

Source: Office for National Statistics, model-based estimates

\section{Conclusions}

Using the model-based estimates of the proportion of households in income poverty assists in the understanding of the geographical patterns of poverty nationally, regionally and locally.

This article has explored spatial variations in the proportions of households in poverty. Some of the most interesting findings come from analysing the spread and distribution of the model-based estimates at a regional level. The analysis has shown that:

- Looking across all MSOAs, Wales, the North East and London had the highest median values of the proportion of households in poverty

- London had the largest spread in terms of the proportion of households in poverty, and the West Midlands had the second widest spread. This large spread indicates that both areas contain MSOAs with both low and high levels of poverty

- This initial analysis seems to supports the general observation that MSOAs in urban centres have higher proportions of households in poverty, while MSOAs in more rural areas have lower proportions of households in poverty 
- The MSOAs surrounding London, in the South East and East of England, generally had the lowest proportions of households in poverty

This analysis has prompted further questions and areas for research which could be explored in the future. The urban/rural differences are interesting and could be explored systematically using the Rural/Urban Definition ${ }^{6}$. Similarly it would be interesting to use the National Statistics 2001 Area Classification ${ }^{7}$ to explore the patterns in the proportion of households in poverty, and whether, as this article suggests, metropolitan type areas have the highest proportions of households in poverty. It would also be interesting to link these estimates to other data sources on different themes, such as unemployment, education and crime; and others that are typically associated with deprivation and poverty.

These are the first estimates of households in poverty at neighbourhood level to be produced and when further estimates are released in the future it will be interesting to see how they change over time; although this analysis will be limited because of the uncertainty associated with the estimates.

As this is the first time ONS has released these model-based estimates of households in poverty, feedback on the quality and utility of these statistics is especially welcomed. Feedback can be directed to: better.info@ons.gov.uk

\footnotetext{
${ }^{6}$ www.ons.gov.uk/about-statistics/geography/products/area-classifications/rural-urban-definition-and-laclassification/rural-urban-definition/index.html

${ }^{7}$ www.statistics.gov.uk/about/methodology by theme/area classification/
} 